\title{
My Husband Is a State Trooper
}

Because of a sideways shadow, the man in the car

Behind me looks as if he has a crease for a head.

I know it is difficult to suspend judgment.

I not only suspend judgment, but suspend

Myself in the bargain, wrung out as surely

As the dishrag over the dripping faucet.

My days are filled with places to be.

In the A.M. it is the kitchen. In the P.M. it is the kitchen

Too, but in between are the plastic aisles, silent, the gleaming

Blacktop, the digitized display mounting higher and higher

As it counts off abandoned calories. My day, in this respect,

Resembles my husband's, but I wish the numbers

To erase me completely. My husband wishes to become

The man behind me in the car, slowing to evade

The ruby digits-not one who waits, each passage

Glowing on his passive face. That his skin were a cage,

And I his keeper-holding the key to zip him up solemnly

By day, and in the evening unzip him again. 